\title{
The role of inferior petrosal sinus sampling in the diagnostic localization of Cushing's disease
}

\author{
Shivanand P. Lad, M.D., Ph.D., Chirag G. Patil, M.D., Edward R. Laws JR., M.D., AND \\ LAURENCE KaTZNELSON, M.D.
}

Department of Neurosurgery, Stanford University School of Medicine, Stanford, California

\begin{abstract}
$\checkmark$ Cushing's syndrome can present a complex problem of differential diagnosis. Of cases in which hypercortisolemia results from an adrenocorticotropic hormone (ACTH)-dependent process, approximately $80 \%$ are due to a pituitary adenoma (Cushing's disease [CD]), 10\% are due to adrenal lesions, and the remaining 10\% are secondary to ectopic ACTH secretion. For patients with CD, surgical removal of the pituitary adenoma is the treatment of choice. Thus, localization of the source of ACTH secretion is critical in guiding timely treatment decisions.

Inferior petrosal sinus sampling (IPSS) is considered to be the gold standard for confirming the origin of ACTH secretion in patients with Cushing's syndrome.

The authors present an overview of IPSS — both the technique and its interpretation—as well as a summary of recent studies. A number of other techniques are discussed including sampling from the cavernous sinus, the jugular vein, and multiple sites to aid the diagnosis and lateralization of ACTH-producing pituitary adenomas. Management is best undertaken by a comprehensive multidisciplinary team taking into account the results of all the biochemical and imaging studies available, to provide the best advice in patient treatment decisions. (DOI: 10.3171/FOC-07/09/E2)
\end{abstract}

\section{Key Words • Cushing's disease • Cushing's syndrome • diagnosis • inferior petrosal sinus sampling}

$\mathrm{C}$ USHING'S syndrome is a clinical condition that results after long-standing exposure to elevated levels of glucocorticoids. ${ }^{33}$ One of the main diagnostic challenges is identifying the underlying cause of hypercortisolism. In approximately $80 \%$ of cases, the cause is an ACTH-dependent process; in approximately $20 \%$ of cases the hypercortisolism is related to primary adrenal causes (that is, ACTH independent). ${ }^{2}$ Of the cases in which the cause is ACTH-dependent, most (approximately 70\% of all cases) are due to a pituitary adenoma (CD); in the remaining cases, the hypercortisolism is secondary to ectopic ACTH secretion, as summarized in Table $1.33,36$ For patients with $\mathrm{CD}$, surgical removal of the pituitary adenoma is the treatment of choice. Thus, localization of the source of $\mathrm{ACTH}$ secretion is critical in guiding timely treatment decisions.

A number of noninvasive biochemical tests are available

Abbreviations used in this paper: $\mathrm{ACTH}=$ adrenocorticotropic hormone; $\mathrm{CD}=$ Cushing's disease; $\mathrm{CRH}=$ corticotropin-releasing hormone; EAS = ectopic ACTH secretion; IPSS = inferior petrosal sinus sampling; $\mathrm{MR}=$ magnetic resonance. to diagnose endogenous hypercortisolism or $\mathrm{CD}$, including assessment of midnight serum or salivary cortisol levels, evaluation of urinary free cortisol levels, and low-dose dexamethasone suppression testing. Although the testing of late-night cortisol levels appears to be the most sensitive and specific screening tool, the urinary free cortisol test and low-dose dexamethasone suppression testing continue to be standard confirmatory tests in the diagnosis of $\mathrm{CD}$. Once an initial diagnosis of pathological hypercortisolemia (Cushing's syndrome) has been confirmed, the task then focuses on determining the source of ACTH secretion.

In the setting of ACTH-dependent Cushing's syndrome (defined by elevated serum ACTH levels), there has been much debate regarding the diagnostic accuracy of tests used in differentiating pituitary $\mathrm{CD}$ from ectopic ACTH secretion. ${ }^{35}$ Localization of ectopic ACTH-secreting tumors is challenging and primarily relies on multimodal imaging and assessment of serum biomarkers. ${ }^{13,14}$ The most common tumors causing ectopic ACTH secretion are summarized in Table $2.19,21$

Conventional imaging studies, including computed tomography and MR imaging, have relatively poor sensi- 
TABLE 1

Causes of Cushing's syndrome*

\begin{tabular}{cc}
\hline \hline Cause & Percentage of Cases $\dagger$ \\
\hline ACTH-dependent causes & 80 \\
CD (pituitary-dependent CS) & 70 \\
EAS & 10 \\
ectopic CRH syndrome & $<1$ \\
ACTH-independent causes & 20 \\
adrenal adenoma & 10 \\
adrenal carcinoma & 8 \\
macronodular adrenal hyperplasia & $<1$ \\
micronodular adrenal hyperplasia & $<1$ \\
\hline
\end{tabular}

$* \mathrm{CS}=$ Cushing syndrome

$\dagger$ Approximate percentages.

tivity and specificity for identifying a pituitary mass lesion. ${ }^{14,16}$ In general, diagnostic imaging with pituitary protocol MR imaging studies using fine sections through the sella turcica, is performed in virtually all patients with suspected CD. In several case series involving adult patients, however, only 40 to $50 \%$ of pituitary adenomas were detected on the basis of MR imaging. ${ }^{14,16}$ Demonstration of a lesion, especially one smaller than $5 \mathrm{~mm}$ in diameter, does not necessary mean that the lesion is producing clinical symptoms, because 10 to $20 \%$ of individuals in the general population harbor a pituitary incidentaloma. ${ }^{6,16}$ In a recent metaanalysis, Ezzat and colleagues ${ }^{9}$ found an overall prevalence of pituitary adenomas of $16.7 \%$ (14.4\% in autopsy studies and $22.5 \%$ in imaging studies). Therefore, it is critical to establish further evidence for ACTH secretion from the pituitary gland before recommending surgery to a patient with a microlesion in the pituitary gland.

In the diagnostic workup of ACTH-dependent Cushing's syndrome, the neuroendocrinologist and neurosurgeon must work together to address the possibility of 1) CD in the face of a nondiagnostic pituitary MR imaging study and 2) an incidental pituitary lesion in conjunction with another microscopic pituitary source or an ectopic source of ACTH.

\section{Inferior Petrosal Sinus Sampling}

The most sensitive method for differentiating between pituitary and ectopic ACTH secretion, ${ }^{19,21}$ IPSS is considered the gold standard for confirming the origin of ACTH secretion in patients with CD. ${ }^{12,38}$ Originally described by Corrigan and colleagues in $1977,{ }^{5}$ unilateral catheterization for selective venous sampling was introduced to differentiate ectopic ACTH secretion from pituitary Cushing's syndrome. Inferior petrosal sinus sampling is recommended in cases of Cushing's syndrome in which clinical, biochemical, or imaging studies have not clearly identified either a pituitary or an ectopic origin of the ACTH production. ${ }^{1}$ The high diagnostic sensitivity, specificity, and accuracy of IPSS have made it a standard tool in the investigation of ACTH-dependent Cushing's syndrome. . $4,31,38,45^{2}$

\section{Technical Considerations}

Bilateral IPSS was initially introduced at the National Institutes of Health by Oldfield and Doppman in the early 1980 s. ${ }^{37,40}$ In the early 1990 s, Oldfield et al..$^{39}$ described the
TABLE 2

Sources of ectopic ACTH secretion*

\begin{tabular}{|c|c|}
\hline Source & Biomarker(s) \\
\hline $\begin{array}{l}\text { neuroendocrine/carcinoid tumors } \\
\text { gastrinoma } \\
\text { medullary thyroid carcinoma } \\
\text { pheochromocytoma } \\
\text { bronchogenic carcinoma } \\
\text { pancreatic carcinoma }\end{array}$ & $\begin{array}{l}\text { 5-HIAA, chromogranin A, \& serotonin } \\
\text { gastrin } \\
\text { calcitonin } \\
\text { catecholamines/metanephrines } \\
\text { hypercalcemia } \\
\text { GHRH }\end{array}$ \\
\hline
\end{tabular}

* GHRH = growth hormone-releasing hormone; 5-HIAA = 5-hydroxyindoleacetic acid.

use of bilateral petrosal sinus sampling with and without administration of CRH for the differential diagnosis of Cushing's syndrome. In this technique, sheaths are inserted bilaterally via the femoral veins and advanced into the internal jugular veins and then into the inferior petrosal sinuses, where blood samples are obtained from each sinus. The plasma ACTH levels in these samples are compared with the levels in samples from a peripheral vein. Samples are taken simultaneously from both central catheters and the peripheral vein. Serial samples for central and peripheral plasma ACTH concentrations are drawn before and after CRH administration ( $1 \mu \mathrm{g} / \mathrm{kg}$ body weight). In CD, a central-to-peripheral (central/peripheral) ACTH gradient results from high ACTH levels in venous drainage from the pituitary (see Fig. 1), and contrasts with the absence of a gradient in ectopic ACTH secretion. Without CRH administration, a basal ratio of central/peripheral ACTH values of 2.0 or greater is strongly indicative of CD.,22,24,34,38,39,41,44 Because ACTH secretion is episodic and sampling can miss the burst of ACTH secretion, however, $\mathrm{CRH}$ is used as a stimulating agent to increase the sensitivity of the test. Plasma ACTH samples are obtained from both inferior petrosal sinuses and peripherally at intervals following CRH administration. A central/peripheral ACTH ratio of 3.0 or greater is strongly indicative of Cushing's disease. ${ }^{39}$ Most patients with EAS have a central/peripheral ACTH ratio of less than 2.0 before and after $\mathrm{CRH}$ administration. $2,23,24,34,38,39,41,44$

Newell-Price et al. ${ }^{35}$ in a systematic analysis that included 21 studies and 569 patients, found that IPSS with CRH stimulation achieved $96 \%$ sensitivity and $100 \%$ specificity in discriminating Cushing's disease from EAS. With the increased adoption of IPSS worldwide and combining various reports of 726 patients who had CD and 112 who had EAS, there were 41 false negatives and seven false positives, providing a diagnostic sensitivity and specificity for IPSS of $94 \% .^{35}$ The results of a review of recent international IPSS studies are summarized in Table 3. In a recent study by Swearingen et al., ${ }^{42}$ lower sensitivity and specificity for predicting a pituitary or an ectopic source were found. In that study, more than $50 \%$ of patients in whom the results of IPSS suggested an ectopic source were found to have an ectopic pituitary tumor. Therefore, lack of central localization by IPSS should lead to a search for an ectopic source, although the presence of a pituitary source should be considered further in such patients. In addition, in approximately $15 \%$ of patients in whom the results of IPSS are positive for central localization, histological confirmation of an ACTH-secreting pituitary tumor is absent. ${ }^{27}$ 
TABLE 3

Summary of published IPSS results

\begin{tabular}{|c|c|c|c|c|}
\hline Author(s) \& Year & No. of Cases of CD & No. of Cases of EAS & Sensitivity (\%) & Specificity (\%) \\
\hline Findling et al., 1991 & 20 & 9 & 100 & 100 \\
\hline Oldfield et al., 1991 & 215 & 20 & 100 & 100 \\
\hline Lopez et al., 1996 & 32 & 0 & 95 & - \\
\hline Booth et al., 1998 & 37 & 0 & 81 & - \\
\hline Doppman et al., 1999 & 510 & - & 99 & - \\
\hline Invitti et al., 1999 & 85 & 10 & 85 & 100 \\
\hline Kaltsas et al., 1999 & 107 & 6 & 97 & 100 \\
\hline Bonelli et al., 2000 & 82 & 10 & 92 & 90 \\
\hline Tsagarakis et al., 2000 & 30 & 4 & 100 & 100 \\
\hline Colao et al., 2001 & 74 & 10 & 90 & 100 \\
\hline Ilias et al., 2004 & 11 & 63 & 94 & 98 \\
\hline Swearingen et al., 2004 & 139 & 10 & 90 & 67 \\
\hline Hernandez et al., 2006 & 0 & 8 & 100 & 100 \\
\hline Lin et al., 2007 & 18 & 0 & 94 & 100 \\
\hline Machado et al., 2007 & 47 & 9 & 92 & 100 \\
\hline Tsagarakis et al., 2007 & 47 & 7 & 98 & 100 \\
\hline
\end{tabular}

These unusual and contradictory findings need to be noted in the interpretation of this test.

The validity of IPSS relies on successful cannulation of the inferior petrosal sinuses (Fig. 1). Digital subtraction angiography must be performed to ensure correct catheter placement and to evaluate venous anatomy properly. A hypoplastic or anomalous inferior petrosal sinus was believed to underlie the false-negative IPSS results that were obtained in $0.8 \%$ of the patients in a large case series (501 patients). ${ }^{8}$ These patients were subsequently found to have surgically proven $\mathrm{CD}$. Other causes of ambiguous results include IPSS performed during a period of normal cortisol levels in patients with intermittent ectopic ACTH secretion and false-positive test results caused by $\mathrm{CRH}$-secreting tumors. ${ }^{46}$ Efforts to improve the diagnostic accuracy include additional sampling during IPSS for other anterior pituitary hormones, including prolactin for normalization of ACTH ratios. ${ }^{10}$ When performed by a radiologist experienced in the technique, IPSS is successful in the great majority of procedures, and serious complications such as venous thrombosis, pulmonary embolism, cranial nerve palsy, and brain stem vascular damage are minimized.

\section{Pituitary Lateralization}

Inferior petrosal sinus sampling has limited utility in localization of ACTH-secreting pituitary adenomas within the gland. A literature review, in which the authors analyzed data from 313 cases in which lateralization studies had been performed and used pituitary surgery as the criterion, revealed a range of diagnostic accuracy for localization of IPSS between 50 and $100 \% .{ }^{35}$ A gradient of 1.4 or greater across both sides of the pituitary correctly predicted tumor location in $78 \%$ of cases. ${ }^{7,37}$ Booth et al. ${ }^{3}$ compared the efficacy of IPSS and the results of imaging studies for localization of pituitary tumors and demonstrated $70 \%$ likelihood of accurate localization using IPSS compared with $49 \%$ using imaging.

\begin{abstract}
Alternative Sampling Methods
Jugular Venous Sampling

It has been suggested that stopping cannulation at the level of the jugular vein and using jugular venous sampling may be a simpler alternative for localizing ACTH-secreting tumors, given the slightly higher technical demand of cannulating the petrosal sinus (that is, IPSS). ${ }^{7}$ Ilias et al. ${ }^{18}$ recently compared the results of jugular vein sampling and IPSS in 74 patients who had surgically confirmed CD and 11 patients with ectopic ACTH secretion. The specificity was $100 \%$ for both techniques, but the sensitivity of IPSS was $94 \%$ compared with $83 \%$ for jugular vein sampling. As might be expected, ACTH values and central/peripheral ratios from jugular samples are usually lower than IPSS ratios due to dilution within the jugular vein and are therefore not as reliable.
\end{abstract}

\section{Cavernous Sinus Sampling}

Cavernous sinus sampling has also been suggested as an alternative to IPSS. ${ }^{25}$ Because the cavernous sinuses are closer to the pituitary gland, the thought was that this technique would provide greater central/peripheral ACTH gradients without the need for $\mathrm{CRH}$ administration. Cavernous sinus sampling may aid in demonstrating lateralization, but is currently performed by only a small number of neuroradiologists. The technique is similar to that of IPSS described previously, but the catheter tip is extended adjacent to the cavernous sinus and the catheter position is verified by cavernous sinus venography, which is performed by hand injection with a minimum amount of contrast material to avoid such complications as brainstem infarction and venous thrombosis. Venous blood is individually sampled from bilateral cavernous sinuses, with and without CRH stimulation. Fujimura et al. ${ }^{15}$ recently examined the role of superselective cavernous sinus sampling in patients with ACTH-producing pituitary adenomas and found that it provided accurate localization of the functional lesion in $73.3 \%$ without $\mathrm{CRH}$ stimulation and $93.3 \%$ with $\mathrm{CRH}$ 
S. P. Lad et al.

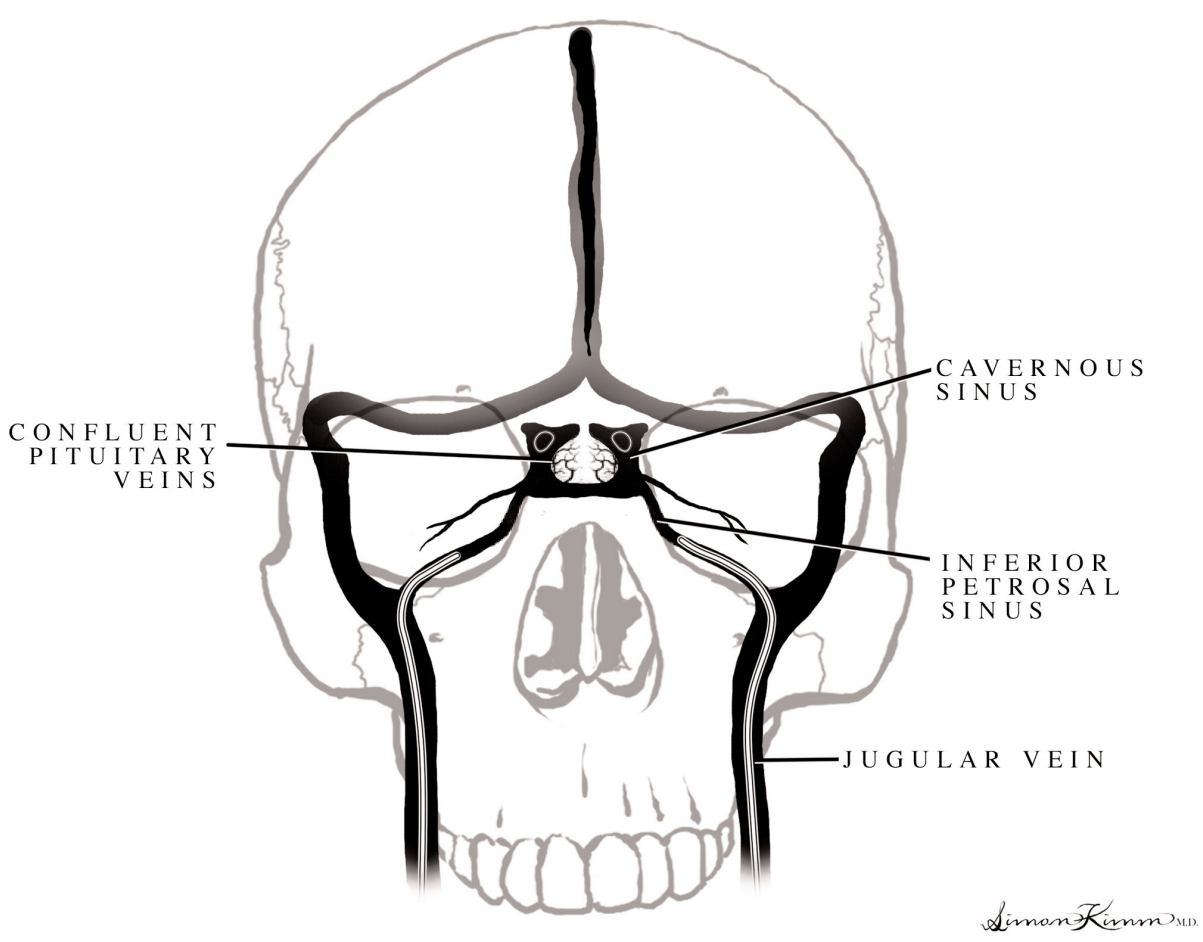

Fig. 1. Cerebral venous anatomy for IPSS.

stimulation. Cavernous sinus sampling appears to be an additional tool in guiding lateralization, but given its increased invasiveness and potentially increased risk of neurological complications in the hands of those who are not familiar with the technique, its use is currently not routine..$^{25}$

\section{Multiple-Site Sampling}

Asymmetrical drainage of blood from the pituitary gland into the cavernous sinus and hence into the inferior petrosal sinus has also been suggested as a potential source for error in adenoma lateralization. Mamelak et al. ${ }^{30}$ have reported shunting of ACTH-rich blood from the cavernous sinus on the side of the adenoma to the contralateral inferior petrosal sinus resulting in false lateralization of the adenoma by IPSS. They demonstrated this asymmetric drainage in $39 \%$ of patients undergoing IPSS. In their study, the results of IPSS correctly predicted adenoma lateralization in $86 \%$ of patients with symmetrical drainage but in only $44 \%$ of patients with an asymmetrical drainage pattern. Kai et al. ${ }^{22}$ recently examined the central/peripheral gradients of ACTH from eight sampling sites. Their findings suggest that the site with the highest ACTH gradient among multiple sampling sites identifies the side on which the tumor is located. If the microadenoma is at the midline of the pituitary gland, however, the intercavernous gradients may falsely identify the side of the tumor. Multiple-site sampling for ACTH levels is more expensive than the singlepoint sampling method, ${ }^{22}$ but it has been suggested that the increased accuracy of adenoma lateralization may help surgeons to preserve normal pituitary tissue when treating these lesions.

\section{Conclusions}

After noninvasive biochemical testing confirms a diagnosis of Cushing's syndrome and a serum ACTH measurement determines the presence of ACTH-dependent Cushing's syndrome, the focus of the evaluation turns to determining the source of ACTH secretion. Inferior petrosal sinus sampling has become the reference gold standard for the identification of ACTH-secreting tumors, but this procedure can be technically demanding and relatively expensive. An analysis of cost was recently performed by Midgette and Aron, ${ }^{32}$ comparing in-hospital evaluation with noninvasive testing followed by IPSS when results were inconclusive. The authors found IPSS favorable in terms of long-term cost-effectiveness and identifying patients who needed pituitary surgery.

In conclusion, Cushing's syndrome can present a complex problem of differential diagnosis. A number of techniques are now emerging to aid in the diagnosis and lateralization of ACTH-producing pituitary adenomas. Management is best undertaken by a comprehensive multidisciplinary team taking into account all the biochemical and imaging studies available, to provide the best advice in treatment decisions.

\section{Acknowledgments}

We thank Dr. Simon Kimm for assistance in preparing Fig. 1.

\section{References}

1. Arnaldi G, Angeli A, Atkinson AB, Bertagna X, Cavagnini F, Chrousos GP, et al: Diagnosis and complications of Cushing's syndrome: a consensus statement. J Clin Endocrinol Metab 88:5593-5602, 2003 
2. Bonelli FS, Huston J, Carpenter PC, Erickson D, Young WF, Meyer FB: Adrenocorticotropic hormone-dependent Cushing's syndrome: sensitivity and specificity of inferior petrosal sinus sampling. AJNR Am J Neuroradiol 21: 690-696, 2000

3. Booth GL, Redelmeier DA, Grosman H, Kovacs K, Smyth HS, Ezzat S: Improved diagnostic accuracy of inferior petrosal sinus sampling over imaging for localizing pituitary pathology in patients with Cushing's disease. J Clin Endocrinol Metab 83: 2291-2295, 1998

4. Colao A, Faggiano A, Pivonello R, Pecori Giraldi F, Cavagnini F, Lombardi G, et al: Inferior petrosal sinus sampling in the differential diagnosis of Cushing's syndrome: results of an Italian multicenter study. Eur J Endocrinol 144:499-507, 2001

5. Corrigan DF, Schaaf M, Whaley RA, Czerwinski CL, Earll JM: Selective venous sampling to differentiate ectopic ACTH secretion from pituitary Cushing's syndrome. N Engl J Med 296: 861-862, 1977

6. Coulon G, Fellmann D, Arbez-Gindre F, Pageaut G: [Latent pituitary adenoma. Autopsy study.] Sem Hop 59:2747-2750, 1983 (Fr)

7. Doppman JL: There is no simple answer to a rare complication of inferior petrosal sinus sampling. AJNR Am J Neuroradiol 20: 191-192, 1999

8. Doppman JL, Chang R, Oldfield EH, Chrousos G, Stratakis CA, Nieman LK: The hypoplastic inferior petrosal sinus: a potential source of false-negative results in petrosal sampling for Cushing's disease. J Clin Endocrinol Metab 84:533-540, 1999

9. Ezzat S, Asa SL, Couldwell WT, Barr CE, Dodge WE, Vance ML, et al: The prevalence of pituitary adenomas: a systematic review. Cancer 101:613-619, 2004

10. Findling JW, Kehoe ME, Raff H: Identification of patients with Cushing's disease with negative pituitary adrenocorticotropin gradients during inferior petrosal sinus sampling: prolactin as an index of pituitary venous effluent. J Clin Endocrinol Metab 89: 6005-6009, 2004

11. Findling JW, Kehoe ME, Shaker JL, Raff H: Routine inferior petrosal sinus sampling in the differential diagnosis of adrenocorticotropin (ACTH)-dependent Cushing's syndrome: early recognition of the occult ectopic ACTH syndrome. J Clin Endocrinol Metab 73:408-413, 1991

12. Findling JW, Raff H: Diagnosis and differential diagnosis of Cushing's syndrome. Endocrinol Metab Clin North Am 30: 729-747, 2001

13. Findling JW, Raff H: Newer diagnostic techniques and problems in Cushing's disease. Endocrinol Metab Clin North Am 28: 191-210, 1999

14. Findling JW, Raff H: Screening and diagnosis of Cushing's syndrome. Endocrinol Metab Clin North Am 34:385-402, 2005

15. Fujimura M, Ikeda H, Takahashi A, Ezura M, Yoshimoto T, Tominaga T: Diagnostic value of super-selective bilateral cavernous sinus sampling with hypothalamic stimulating hormone loading in patients with ACTH-producing pituitary adenoma. Neurol Res 27:11-15, 2005

16. Hall WA, Luciano MG, Doppman JL, Patronas NJ, Oldfield EH: Pituitary magnetic resonance imaging in normal human volunteers: occult adenomas in the general population. Ann Intern Med 120:817-820, 1994

17. Hernandez I, Espinosa-de-los-Monteros AL, Mendoza V, Cheng S, Molina M, Sosa E, et al: Ectopic ACTH-secreting syndrome: a single center experience report with a high prevalence of occult tumor. Arch Med Res 37:976-980, 2006

18. Ilias I, Chang R, Pacak K, Oldfield EH, Wesley R, Doppman J, et al: Jugular venous sampling: an alternative to petrosal sinus sampling for the diagnostic evaluation of adrenocorticotropic hormone-dependent Cushing's syndrome. J Clin Endocrinol Metab 89:3795-3800, 2004

19. Ilias I, Torpy DJ, Pacak K, Mullen N, Wesley RA, Nieman LK: Cushing's syndrome due to ectopic corticotropin secretion: twen- ty years' experience at the National Institutes of Health. J Clin Endocrinol Metab 90:4955-4962, 2005

20. Invitti C, Pecori Giraldi F, Cavagnini F: Inferior petrosal sinus sampling in patients with Cushing's syndrome and contradictory responses to dynamic testing. Clin Endocrinol (Oxf) 51: 255-257, 1999

21. Isidori AM, Kaltsas GA, Pozza C, Frajese V, Newell-Price J, Reznek RH, et al: The ectopic adrenocorticotropin syndrome: clinical features, diagnosis, management, and long-term followup. J Clin Endocrinol Metab 91:371-377, 2006

22. Kai Y, Hamada J, Nishi T, Morioka M, Mizuno T, Ushio Y: Usefulness of multiple-site venous sampling in the treatment of adrenocorticotropic hormone-producing pituitary adenomas. Surg Neurol 59:292-299, 2003

23. Kaltsas GA, Giannulis MG, Newell-Price JD, Dacie JE, Thakkar C, Afshar F, et al: A critical analysis of the value of simultaneous inferior petrosal sinus sampling in Cushing's disease and the occult ectopic adrenocorticotropin syndrome. J Clin Endocrinol Metab 84:487-492, 1999

24. Kaskarelis IS, Tsatalou EG, Benakis SV, Malagari K, Komninos I, Vassiliadi D, et al: Bilateral inferior petrosal sinuses sampling in the routine investigation of Cushing's syndrome: a comparison with MRI. AJR Am J Roentgenol 187:562-570, 2006

25. Lefournier V, Martinie M, Vasdev A, Bessou P, Passagia JG, Labat-Moleur F, et al: Accuracy of bilateral inferior petrosal or cavernous sinuses sampling in predicting the lateralization of Cushing's disease pituitary microadenoma: influence of catheter position and anatomy of venous drainage. J Clin Endocrinol Metab 88: 196-203, 2003

26. Lin LY, Teng MM, Huang CI, Ma WY, Wang KL, Lin HD, et al: Assessment of bilateral inferior petrosal sinus sampling (BIPSS) in the diagnosis of Cushing's disease. J Chin Med Assoc 70: 4-10, 2007

27. Locatelli M, Vance ML, Laws ER: Clinical review: the strategy of immediate reoperation for transsphenoidal surgery for Cushing's disease. J Clin Endocrinol Metab 90:5478-5482, 2005

28. López J, Barceló B, Lucas T, Salame F, Alameda C, Boronat M, et al: Petrosal sinus sampling for diagnosis of Cushing's disease: evidence of false negative results. Clin Endocrinol (Oxf) 45: 147-156, 1996

29. Machado MC, de Sa SV, Domenice S, Fragoso MC, Puglia P, Pereira MA, et al: The role of desmopressin in bilateral and simultaneous inferior petrosal sinus sampling for differential diagnosis of ACTH-dependent Cushing's syndrome. Clin Endocrinol (Oxf) 66: 136-142, 2007

30. Mamelak AN, Dowd CF, Tyrrell JB, McDonald JF, Wilson CB: Venous angiography is needed to interpret inferior petrosal sinus and cavernous sinus sampling data for lateralizing adrenocorticotropin-secreting adenomas. J Clin Endocrinol Metab 81: 475-481, 1996

31. McCance DR, McIlrath E, McNeill A, Gordon DS, Hadden DR, Kennedy L, et al: Bilateral inferior petrosal sinus sampling as a routine procedure in ACTH-dependent Cushing's syndrome. Clin Endocrinol (Oxf) 30:157-166, 1989

32. Midgette AS, Aron DC: High-dose dexamethasone suppression testing versus inferior petrosal sinus sampling in the differential diagnosis of adrenocorticotropin-dependent Cushing's syndrome: a decision analysis. Am J Med Sci 309:162-170, 1995

33. Newell-Price J, Bertagna X, Grossman AB, Nieman LK: Cushing's syndrome. Lancet 367:1605-1617, 2006

34. Newell-Price J, Perry L, Medbak S, Monson J, Savage M, Besser $\mathrm{M}$, et al: A combined test using desmopressin and corticotropinreleasing hormone in the differential diagnosis of Cushing's syndrome. J Clin Endocrinol Metab 82:176-181, 1997

35. Newell-Price J, Trainer P, Besser M, Grossman A: The diagnosis and differential diagnosis of Cushing's syndrome and pseudoCushing's states. Endocr Rev 19:647-672, 1998

36. Nieman LK, Ilias I: Evaluation and treatment of Cushing's syndrome. Am J Med 118:1340-1346, 2005 
37. Oldfield EH, Chrousos GP, Schulte HM, Schaaf M, McKeever PE, Krudy AG, et al: Preoperative lateralization of ACTH-secreting pituitary microadenomas by bilateral and simultaneous inferior petrosal venous sinus sampling. N Engl J Med 312:100-103, 1985

38. Oldfield EH, Doppman JL: Petrosal versus cavernous sinus sampling. J Neurosurg 89:890-893, 1998

39. Oldfield EH, Doppman JL, Nieman LK, Chrousos GP, Miller DL, Katz DA, et al: Petrosal sinus sampling with and without corticotropin-releasing hormone for the differential diagnosis of Cushing's syndrome. N Engl J Med 325:897-905, 1991

40. Oldfield EH, Girton ME, Doppman JL: Absence of intercavernous venous mixing: evidence supporting lateralization of pituitary microadenomas by venous sampling. J Clin Endocrinol Metab 61:644-647, 1985

41. Pecori Giraldi F, Invitti C, Cavagnini F, Study Group of the Italian Society of Endocrinology and the Pathophysiology of the Hypothalamic-pituitary-adrenal axis: The corticotropin-releasing hormone test in the diagnosis of ACTH-dependent Cushing's syndrome: a reappraisal. Clin Endocrinol (Oxf) 54:601-607, 2001

42. Swearingen B, Katznelson L, Miller K, Grinspoon S, Waltman A, Dorer DJ, et al: Diagnostic errors after inferior petrosal sinus sampling. J Clin Endocrinol Metab 89:3752-3763, 2004

43. Tsagarakis S, Kaskarelis IS, Kokkoris P, Malagari C, Thalassinos $\mathrm{N}$ : The application of a combined stimulation with CRH and desmopressin during bilateral inferior petrosal sinus sampling in patients with Cushing's syndrome. Clin Endocrinol (Oxf) 52: 355-361, 2000

44. Tsagarakis S, Vassiliadi D, Kaskarelis IS, Komninos J, Souvatzoglou $\mathrm{E}$, Thalassinos N: The application of the combined corticotropin-releasing hormone plus desmopressin stimulation during petrosal sinus sampling is both sensitive and specific in differentiating patients with Cushing's Disease from patients with the occult ectopic adrenocorticotropin syndrome. J Clin Endocrinol Metab 92:2080-2086, 2007

45. Wiggam MI, Heaney AP, McIlrath EM, McCance DR, Sheridan B, Hadden DR, et al: Bilateral inferior petrosal sinus sampling in the differential diagnosis of adrenocorticotropin-dependent Cushing's syndrome: a comparison with other diagnostic tests. J Clin Endocrinol Metab 85:1525-1532, 2000

46. Young J, Deneux C, Grino M, Oliver C, Chanson P, Schaison G: Pitfall of petrosal sinus sampling in a Cushing's syndrome secondary to ectopic adrenocorticotropin-corticotropin releasing hormone (ACTH-CRH) secretion. J Clin Endocrinol Metab 83: 305-308, 1998

Manuscript submitted June 19, 2007.

Accepted July 26, 2007.

Address correspondence to: Shivanand P. Lad, M.D., Ph.D., Stanford Hospital, Department of Neurosurgery, 300 Pasteur Drive Room R281 MC5327, Stanford, California 94305. email:nlad@ stanford.edu. 